\title{
Communication gap between health professionals and patients on anticoagulant therapy in the WhatsApp era
}

\author{
Comunicação deficiente entre profissionais de saúde e pacientes sobre o tratamento \\ anticoagulante na era do WhatsApp
}

Pai Ching Y $u^{1}$, Bruno Caramelli ${ }^{\top}$

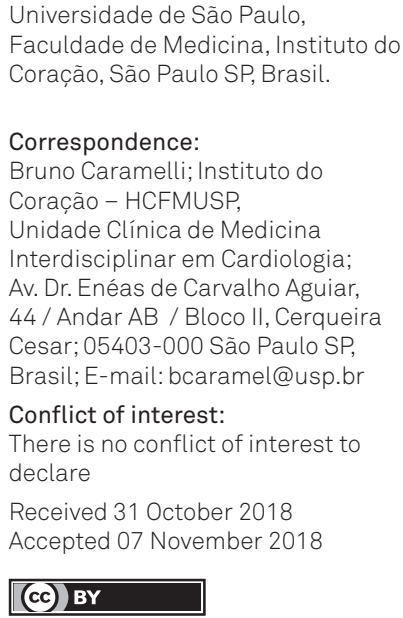

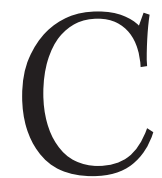

ardiovascular diseases are the leading global cause of death. According to the World Health Organization, 17.9 million people die every year due to cardiovascular diseases, which are responsible for $31 \%$ of all global deaths ${ }^{1}$. Heart attacks and strokes, the main primary manifestations of cardiovascular diseases, remain the two leading causes of premature deaths in The Global Burden of Disease 2016 Study². Worldwide, stroke is the second most common cause of mortality and the third most common cause of disability. Approximately $80 \%$ of strokes are due to ischemic cerebral infarction and $20 \%$ to brain hemorrhage.

Atrial fibrillation, the most frequent cardiac arrhythmia, is associated with high mortality and morbidity, and the main cause of embolic events involved in the genesis of stroke. A high incidence and prevalence of atrial fibrillation is observed in the elderly population and it is independently associated with a two-fold increased risk of all-cause mortality in women and a 1.5-fold increase in men. It is well known that oral anticoagulation therapy can reduce the risk of ischemic stroke and other embolic events by about two-thirds, irrespective of the baseline risk ${ }^{3}$. However, the major concern about anticoagulation therapy is the increased risk of bleeding, especially events that require hospitalization, transfusion, surgery, or serious bleeding complications like intracranial hemorrhage.

Several antithrombotic therapies are available nowadays, basically divided onto two classes-vitamin $\mathrm{K}$ antagonists or direct oral anticoagulant agents. Warfarin and other vitamin $\mathrm{K}$ antagonists were the first anticoagulants used in atrial fibrillation patients. Warfarin is widely available and is associated with a large amount of clinical experience in its long-term use. However, its prescription requires frequent monitoring, as the dose changes according to the international normalized ratio. On the other hand, direct oral anticoagulant agents, including the direct thrombin inhibitor (dabigatran) and the factor Xa inhibitors (apixaban, edoxaban, and rivaroxaban) are suitable alternatives to vitamin $\mathrm{K}$ antagonists for stroke prevention in atrial fibrillation. Their use in clinical practice is increasing rapidly due to the advantage of not requiring regular anticoagulation monitoring. Regardless of the prescribed anticoagulant therapy, it is essential that all patients are oriented in relation to the risk of hemorrhage and bleeding complications related to treatment and the importance of adherence to prevent stroke and thrombotic events.

In this issue of Arquivos de Neuro-Psiquiatria, Leitão et al. ${ }^{4}$ report alarming data about the lack of knowledge of antithrombotic therapy among patients with atrial fibrillation. The authors initially interviewed 150 patients and included 131 of those on anticoagulation therapy in this study. All the patients were using vitamin Kantagonists exclusively. The main results of the study show that more than half the patients (53.1\%) did not have the basic knowledge about the risk of oral anticoagulant therapy. Among the patients who were informed about the risks, only $25.9 \%$ could identify stroke as a risk of nonadherence. More than one-third (37.7\%) of the patients had no information about any risk related to anticoagulant treatment. These findings raise serious concerns about the safety and efficacy of anticoagulant therapy among our population. 
The prescription of vitamin $\mathrm{K}$ antagonist agents requires regular control of an optimal range for the international normalized ratio, to prevent thromboembolic events without exposing patients to unacceptably high risks of bleeding. Even in a hospital specialized in cardiology, we found that $32 \%$ of the patients with atrial fibrillation were not receiving any anticoagulant therapy ${ }^{5}$.

The low comprehension and lack of knowledge of patients with atrial fibrillation on antithrombotic therapy may directly affect anticoagulation therapy control and expose patients to adverse events, like bleeding complications. It is well known that adequate health knowledge and good understanding of health information is directly related to good patient self-care and higher motivation and adherence to treatment with oral anticoagulants ${ }^{6}$. Previous studies have documented similar results on insufficient information among patients on anticoagulant treatment in Brazil ${ }^{7,8}$.

In a modern world that sends more than 55 billion WhatsApp messages per day, the scenario depicted by the Leitão et al. ${ }^{4}$ study is unacceptable. As with every medical treatment, the correct and safe use of anticoagulant therapy among our patients is paramount and tells us that we urgently need to improve the communication of information to our patients.

\section{References}

1. World Health Organization. World hearth day: scale up prevention of hearth attack and stroke.Geneva: World Health Organization; [date unknown] [cited 2018 oct. 29]. Available from: https://www.who.int/ cardiovascular_diseases/world-heart-day/en/

2. Naghavi M, Abajobir AA, Abbafati C, Abbas KM, Abd-Allah F, Abera SF et al. Global, regional, and national age-sex specific mortality for 264 causes of death, 1980-2016: a systematic analysis for the Global Burden of Disease Study 2016. Lancet. 2017 Sep;390(10100):1151-210. https://doi.org/10.1016/S0140-6736(17)32152-9

3. Kirchhof P, Benussi S, Kotecha D, Ahlsson A, Atar D, Casadei B. et al. 2016 ESC Guidelines for the management of atrial fibrillation developed in collaboration with EACTS. Eur Heart J. 2016 Oct;37(38):2893-962. https://doi.org/10.1093/eurheartj/ehw210

4. Leitão JM, Moreira FMDS, Thiel IE, Spricido IY, Silva RHM, Zétola VF. Alarming lack of knowledge about antithrombotic therapy among patients with atrial fibrillation. Arq Neuropsiquiatr. 2018;76(12):807-11. https://doi.org/10.1590/0004-282X20180126
5. Fornari LS, Calderaro D, Nassar IB, Lauretti C, Nakamura L, Bagnatori R et al. Misuse of antithrombotic therapy in atrial fibrillation patients: frequent, pervasive and persistent. J Thromb Thrombolysis. 2007 Feb;23(1):65-71. https://doi.org/10.1007/s11239-006-9012-9

6. Cabellos-García AC, Martínez-Sabater A, Castro-Sánchez E, Kangasniemi M, Juárez-Vela R, Gea-Caballero V. Relation between health literacy, self-care and adherence to treatment with oral anticoagulants in adults: a narrative systematic review. BMC Public Health. 2018 Oct;18(1):1157. https://doi.org/10.1186/s12889-018-6070-9

7. Souza TF, Colet CF, Heineck I. Knowledge and information levels and adherence to oral anticoagulant therapy with warfarin in patients attending primary health care services. J Vasc Bras. 2018 Apr-Jun;17(2):109-16.

8. Henn CB, Rabelo ER, Boaz M, Souza EN. [Knowledge on chronic oral anticoagulation of patients followed up in a specialized outpatient clinic]. Rev Gaucha Enferm. 2008 Jun;29(2):207-13. Portuguese. 